\title{
HEALTH AND SAFETY DURING CLINICAL PRACTICES AND PRE-GRADUATION INTERNSHIPS OF STUDENTS TRAINING TO BECOME A NURSE
}

\author{
Genoveva Ragiovska-Monova ${ }^{1}$, Daniel Monov ${ }^{2}$, Diana Grozdeva ${ }^{1}$ \\ ${ }^{1}$ Department of Health Care, Faculty of Public Health, Medical University of Varna \\ ${ }^{2}$ TRS Health Inspector, Medical College, Medical University of Varna
}

\section{ABSTRACT \\ INTRODUCTION}

Damaged health, injuries and illnesses related to the workplace, are causes of immense human suffering. Safety is essential during the working process or the ongoing training. Each participant in the therapy and health care has a responsibility to comply with the measures for healthy and safe working conditions. During their training, students in the Nurse program are part of this process and have an obligation and responsibility to the patients, the staff and themselves to ensure healthy and safe working conditions.

AIM: The aim of the present study is to explore the knowledge about the safety of students in the Nurse program at the Medical University of Varna, during clinical practice and internship before graduating.

MATERIALS AND METHODS: This paper examines the opinions of 146 of the total 205 students from $1^{\text {st }}$ to $4^{\text {th }}$ year in the Nurse program at the Medical University of Varna. The study was conducted by direct anonymous questionnaire for the period from January to March, 2016. Analysis of literature sources and a questionnaire method were used. The data were processed by statistical and graphical analysis.

RESULTS: The opinion of the respondents is firm regarding the need for protective equipment during clinical practice and internship before graduating. A significant part of the students cited as the most frequent incidents: contamination of the skin with blood and body fluids, followed by pricks from sharp objects (needles), as well as aggression by patients.

The analysis of the results shows that more than a half of the surveyed students are familiar with the regulations for the protection of medical personnel in an accident.

Keywords: students, safety, nurse

Address for correspondence:

Genoveva Ragyovska - Monova

Department of Health Care

Faculty of Public Health

Medical University of Varna

55 Marin Drinov St.

9002 Varna

e-mail: gevir@abv.bg 
Genoveva Ragiovska-Monova, Daniel Monov, Diana Grozdeva

\section{INTRODUCTION}

Damaged health, injuries and illnesses related to the workplace become reasons for severe human suffering. Safety is crucial when conducting any type of work or training. Every participant in the healing process, providing care, bears responsibility to keep and apply rules of health and safety. Students studying to be a nurse are a part of this process during their studies and have obligations towards their patients, personnel and themselves to provide the uppermost standard of health and safety when working.

\section{AIM}

The aim of the following survey is to analyse the opinion of students enrolled in the "Nurse" program at the Medical University of Varna, regarding their knowledge about health and safety norms during clinical practice and pre-graduation internship.

\section{MATERIALS AND METHODS}

The opinions of 146 out of 205 students from first to fourth year enrolled in the Nurse program at the Medical University of Varna have been analysed. The survey was conducted using direct anonymous questionnaire for the period January - March, 2016. The methods used include analysis of literature sources and survey methods. The results have been processed using a statistical and graphical analysis.

\section{RESULTS}

The number of the participants in the conducted survey was 146 (72.22\%) out of all 205 students in the Nurse program (Fig. 1).

From their first day in the program, all newly admitted students are given health and safety instructions. For that purpose, a journal is kept with

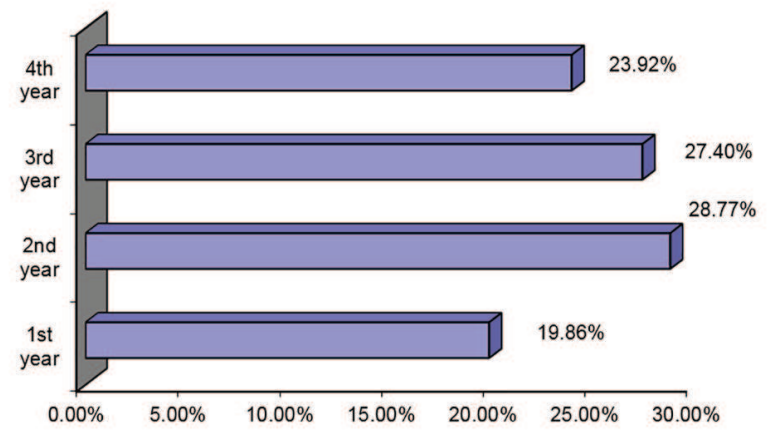

Fig. 1. Distribution of students surveyed (by year) students' names and signatures, showing they have been instructed. Since the beginning of the training of future nurses, the rules of health and safety within the university training facilities are discussed. Students from other courses also partake in such instruction sessions at the beginning of each semester, also being registered in the relevant journal containing their own signature. This leads to the question whether protective equipment is needed in the nurse's work. The opinion of those surveyed is definitely in favour of the need of such equipment during clinical practice and pre-graduation internships. Almost all of those surveyed have given an affirmative answer (98.63\%) (Fig. 2).

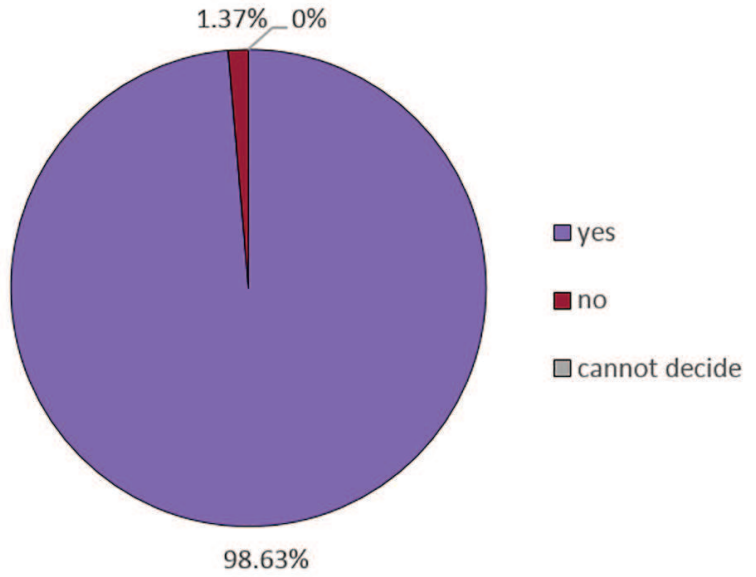

Fig. 2. The need of protective equipment in the nurse's work

We gave those who were questioned the chance to arrange universal protective equipment by importance. Results coincide with those realistically used in practice. First place in importance is given to gloves $-74.66 \%$. According to the students the second most important piece of equipment is glasses $65.07 \%$. Third comes the mask $-48.63 \%$, and last work clothing - $34.25 \%$ (Table 1) (Fig. 3).

Table 1. Universal protective equipment

\begin{tabular}{clcc}
\hline$№$ & Safety equipment & Number & $\%$ \\
1 & Gloves & 109 & $74,65 \%$ \\
2 & Glasses & 95 & $65,07 \%$ \\
3 & Masks & 71 & $48,63 \%$ \\
4 & Work clothing & 50 & $34,25 \%$ \\
\hline
\end{tabular}




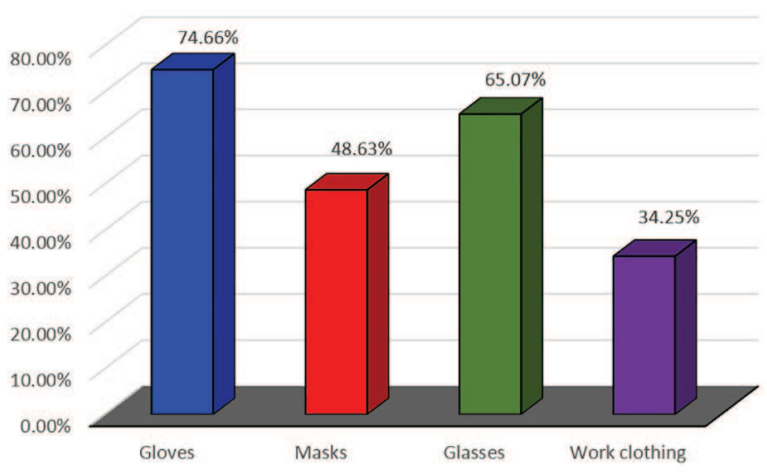

Fig. 3. Most commonly used protective equipment

Every participant in the process of providing care and healing has a goal and obligation to prevent medical care related infections and to protect the personnel and third parties. Also, they have to keep hygiene rules and precautions (3).

In reality, while doing clinical practice or internship, students are obliged to work with gloves on. During the years of their training they acquire the habit of using gloves for their own and their patients' safety. It is a rarity to find safety glasses used by nurses in other wards; however, the surveyed students realise the necessity of having them as reliable protective equipment. Masks are also commonly used, especially if the nurse is ill, to protect the patients and the rest of the staff from infection.

Due to the health and safety instructions being a compulsory element at the beginning of each semester, we intended to find if students remember being instructed. More than half claim they have received such instructions each semester - 57.53\%. Another $32.19 \%$ claim instructions took place in each facility. Actually, each lecturer gives such briefings verbally on the first day of entering new university facilities. According to $22.60 \%$ of those surveyed, there were instructions at the beginning of each academic year. A part of the students claim they have been instructed at the beginning of their course $-7.53 \%$. Some $8.9 \%$ cannot remember having been instructed, and $1.37 \%$ claim they have never been instructed.

In medical practice, implementation of given tasks is important but so are safe working conditions, working environment and medical care. A nurse's responsibilities and rights are a core element of their professional obligations. That is the reason why it

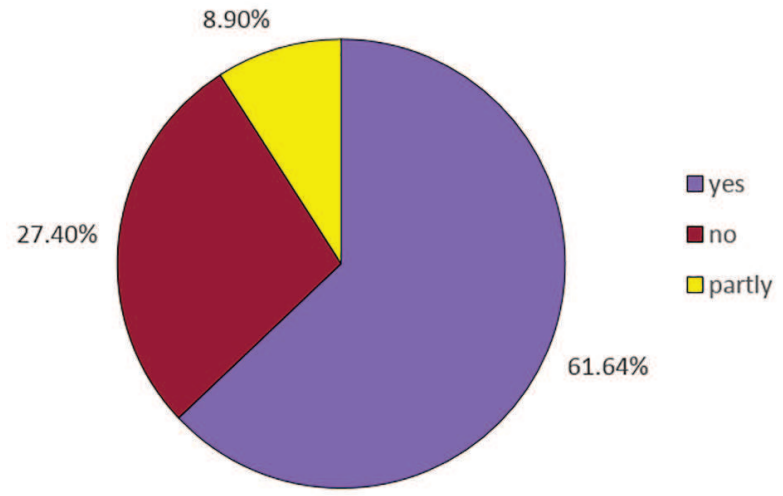

Fig. 4. Are you familiar with the regulatory norms of safety for medical personnel?

was important for us to check if future nurses have been introduced to the regulatory norms (Fig. 4).

The traumatism level whilst undertaking regular work tasks is considered to be one of the most important signs of both quality of work and how well health and safety regulations are followed. The reasons are plenty, however, sometimes the outcome is lost human life, disability, suffering and financial damage.

How students rate the most common accidents in the clinical practice or internship was important to our survey (Fig. 5).

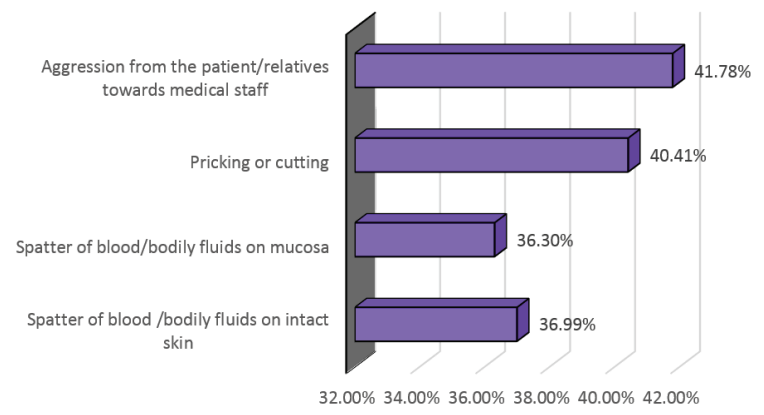

Fig. 5. Most common accidents during clinical practice or pre-graduation internship

The majority of students surveyed identify aggression as a leading cause of accidents - $41.78 \%$. A close second is injury from pricking or cutting $40.41 \%$. Splashing of blood on skin and on mucous membranes gives almost identical results $-36.99 \%$ and $36.30 \%$, respectively. Most of the respondents have given more than one answer. It was a surprise for us to find that students have precisely pointed out aggression as a leading one. Perhaps they have been 
influenced by their observations during their time of clinical practice and by the more and more frequent similar accidents with nurses and doctors, shown in the mass media.

\section{CONCLUSIONS}

Analysing the results from the conducted survey allows us to mark the following key points:

1. More than half of the surveyed students are familiar with the regulatory norms to protect the medical personnel when an accident occurs.

2 . The necessity of protective equipment during clinical practices and pre-graduation internships is explicitly pointed out by the respondents.

3. Gloves, glasses and masks are of uppermost importance in terms of personal protective equipment.

4. A big part of students identify aggression as the most common accident: aggression from patients, pricking with sharp objects, contamination of skin with blood and bodily fluids.

Final words

Workplace safety is a problem of increasing significance. Results from a number of reports prove that a nurse is one of the most difficult professions. That is why students have to be familiar with and respect the safe workplace norms.

\section{REFERENCES}

1. Ordinance №3 of 19.04.2001. The minimum requirements for safety and health of workers using personal protective equipment at the workplace. SG. 2001; 46 (Effective 16.08.2001. Issue 6 / 2001: 11, S.1, №36b amend. Suppl. SG, Issue 40 / 2008).

2. Petrova N, Georgieva L. Current policies for health promotion in the workplace magazine. Social Medicine. 2015; 2:15-17.

3. Spassova N, Karastoyanova E, Pachedzhiev A. Handbook of Workplace Safety. BULVEST 2000; 2008:11-13.

4. European Parliament. Report on breast cancer in the European Union. 2003 (RR-497647EN.doc).

5. Spartt J, Donegan W. Cancer of the Breast. Elsevier Science-Saunders (USA); 2002:111-133.

6. http://www.who.int/ 